min succoeded pain; and all appeared to proceed farouratily. It was howorec observed, that during this early stave, her countemance was unvsually pale and anxious, with headache, yawning and occasional vomiting. At half past 9 A.x. "a pain was taken" by my assistant. This pirital examination of the os uteri appesed the immediate exciting cause of the first paroxysm of convulsion, which was sudden in its attack, and continued in a most severe form for a whole hour, during which period the face was rery livid and suffused, the veins of the head and neck were manch distended, the carotids beat violently, and the contontion of the countenance and general convulsions were most fearful, and the danger from asphyxia was imminent. To relieve this alarming state the lancet was immediately put into requisition, and a vein in each arm was opened; this appeared to shorten the duration of the fit, and the suocoeding paroxysms, which recurred at short intervals, did not last more than about twenty minutes. They, however, followed each other in such rapid succession, that I resolved to empty the uterus. The os uteri and external parts being sufficiently dilated, and the head presenting, I determined upon perforating the head, and extracting. the fotus by craniotomy; this was speedily accomplished, and the placenta was expelled by the natural uterine contractions in about five minutes. There was hardly any discharge, and the convulsions subsided; consciousness was restored, the patient took some grucl, and appeared comfortable; she, however, in reply to my inquiries, said that her head and her body generally felt hot. She remained in this quiet state for one hour, when she was again attacked suddenly with a most violent convulsion. The vein in the arm was again opened, and the exterual jugular, which was enormously distended (being quite as thick as my finger), was also punetured, and a considerable amount of blood was then away. The head was shared; ice was applied to it, and mustard cataplasms to the nape of the neck and legs, and hot applications to the feet, and cold water was dashed into the face, and a turpentinc enema was administered. Btill the convulsions persisted, and the frightful suffocation with livid lips and turgid countenance exceeded anything I had ever witnessed, and led me to reflect upon the parallelism (to my mind) between this case and epilepsy, and the possible relief tracheotomy might afford, as recommended by Dr. Marshall Hall in the latter dire disease. Having before me evidence of the spasmodic closure of the glottis, the constriction of the throat from contraction of its muscles, and the interrupted circulation from the cerebrum, under which I felt convinced the patient must shortly expire, I resolved upon opening the trachea. This, howerer, was no easy task in the middle of the country, and without the usual appliances for the performance of so delicate an operation; and, to add to the difficulty, the patient had an enlarged thyroid gland. I became desirous of having a consultation, and accordingly sent to Wrexham, a distance of fire miles, for "Cooper's case" and my trachea pipe; and by the same messenger, I dispatched a note to request a medical friend to come over, and give me the benefit of his advice and assistance, being anxious to hare a consultation upon the propriety of a such a step, as I was not aware of tracheotomy having been recommended by any authorities in precisely such an emergency. The persistence and threatening nature of the paroxysms, and the momentary expectation of death, made me resolve, at all risks, to adopt that measure which Dr. Marshall Hall recommends " as a preventative and security against spasmodic laryngismus and its effects, viz., convulsions, and the injury apt to be inflicted on the cerebrum and medulla oblongata."

Having searched the house in vain for a tube which would supply the place of a trachea pipe, I ultimately made use of an old silver tube belonging to a caustic case, the end of which I broke off, and securely attached it to a long tape. Thus provided, with the aid of the few things - small pocket-case contained, I succeeded in opening the trachea. The enlarged thyroid gland, and consequent great depth of the wound, added greatly to the difficulty, which frant of the neck; these happily esouped injons, and the mount of blood lost during the operation wa very triting. The trachea being opened, a vast quantity of mosoens cretion was forcibly ejected; the tube was introduced, and secured in its place, and the breathing was immediately established through it, with a most decided improwement in the general appearnee of the patient. The conntemance lost its lividity, which never again returned; the fectures were more tranquil; and the veins of the head and nock collapsed, and did not again become distended. The convulsions did not, however, cease ; but they become leas frequent and less violent. In due course of time Mr. Lewis arrived, bringing with him a trachea pipe, which was substituted for my temporary contrivance. He expresed, in warm terms, his satisfaction at the relief the operation had afforiled, and suggested further depletion; and 28 the jugular vein cessed to become distended, a vein in the arm was opened with manifest advantage. The turpentine enemata were repeated, and mustard cataplasms continued. Six leeches were applied to the temple, and the catheter was introduced. The convulsions did not cease until one o'clock in the morning, and a comatose state supervened; the limbs were motionless, the power of deglutition gone, and life seemed ebbing. Enemata were assiduously administered, composed of good broth, alternately with egg and brandy, and occasionally egg and turpentine (by my assistant, who remained the night); they seemed to revive the patient considerably. At eleven o'clock the next morning Mr. Lewis and I again visited our patient, and found her rather revived by a turpentine and egg clyster, which my assistant had just administered, and which seemed to restore her consciousness and improve her pulse in some degree. As she had sunk a good deal in the bed, we attempted to improve her position, and slightly and carefully elevated her head and thorax ; and in a very few minutes she expired (having survived delivery twentyfour hours, and the operation about twenty-one hours). This event afforded me an additional instance of the fatal effects of disturbing or moving patients when the powers of life are in a very depressed state.

In conclusion I may observe, that the marked improve ment in the lividity, and tumefaction of the face and neck, which was very great, has left a most farourable impression on $\mathrm{my}$ mind of the great utility of tracheotomy in such cases.

Wresham, August 1854.

\section{CASE OF LITHOTOMY IN THE FEMALE: WITH REMARKS.}

By W. J. SQUARE, Esq., Surgeon to the South Devon and Fast Cornwall Hospital.

Is a clinical lecture on calculus in the female bladder, reported in the Medical Times and Gazette of 29th July, Mr. Fergusson remarks :

"A very interesting and important problem remains yet to be solved, - which is the best way of extracting a stone from the female bladder?

"I hope that the time nry arrive, when a true solution will enable the operation to be performed without incurring the hazard or annoyance of an incontinence of urine, which I am sorry to say is but too apt to follow any operation involving the female urethra."

Such an observation, emanating from such a distinguished surgeon, appears to me to demand the publication of every case bearing upon the subject of lithotomy in the female.

I entertain the hope that the publication of the isolated case which I now record, together with Mr. Fergusson's remarks, may evoke from the profession such an aggregate of experience, as will in future warrant a more decided and constant rule of practice than at present exists.

CASE. Nary Cook, aged 30, was admitted into the South Deron and East Cornwall Hospital at Plymouth, June 3rd, 1850 . She had suffercd more or less from painful micturition for five years; during the last year her distress had 


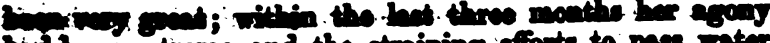

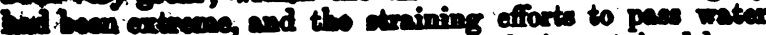
sheat conetant. The urine was neentral ; it contained large mantities of mucus and blood. The tongre was dry and cinted; the appetite was very bad; the pulse was feeble and frequent; sleep was almost absent. Sounding gare ber great agony; but the stone, which appeared to be of ing cise, was immediately struck. I ordered ordinary diet, - wrm hip bath erery night, and a suppository of ton anins of compound sosp pill at bedtime, and dilute nitric woid, with tinoture of hyoscjamus in a decoction of pareira breve, overy four hours.

June $20 \mathrm{th}$. She was somewhat relieved. The urine contained lees blood and mucus, but was still neutral; the fort to micturate were less frequent and painful.

June 28nd. $\triangle$ staff being pessed into the bladder, I slid a probe-pointed bistoury upon it into the bladder, and made an incision downwards and outwards parallel to the left descending ramus of the os pubis. The sphincter vesice was scancely incised, but at the lower and outer part the incision was about three-fourths of an inch in length. I dilated the wound with the forefinger. The stone was readily grasped, but being very soft, was crushed into numerous fragments by the pressure of the forceps. The fragments were remored fram the bladder by the scoop and syringe.

After the operation, a short gum catheter was placed in the upper part of the wound, and the vagina was plugged with a bladder stuffed with tow. This plan prevented the escape of urine through the wound, and was continued-six days. The plug was then remored, and the bladder eracuated by a female catheter every two hours. On the tenth day she was allowed to pass her urine without the catheter.

On her discharge from the hospital, a month after the operation, her power of retention was almost, but not quite perfect.

In April 1852, Mr. Leamon, Jun., of Tavistock, called on this woman at my request, and found her quite well. She rotained her water perfectly, but when pregnant it passed at times involuntarily.

Judging from the quantity of calculous matter removed, and from the largest segments of the laminæ extracted by the forceps, I estimated the size of the stone to be equal to that of a moderately sized walnut. It was composed principally of phosphate of lime.

The question of lithotrity was entertained by the surgical staff (Messrs. Whipple, Derry, and myself) when the patient entered the hospital; but the extreme agony induced by sounding, the excessive irritability of the bladder, the large amount of mucus and blood mingled with the urine, and the probable large size of the stone, led to a negative decision.

Again, the probability of the stone being of large size made me adopt incision rather than dilatation.

My own conclusions in reference to operative proceeding in cases of stone in the female are-

1. If the bladder is healthy, the urine normal, and the calculus of moderate dimensions, to practise lithotrity.

2. If the bladder is very irritable, the urine containing mucus, or mucus and blood, in anything more than ordinary quantity, and the stone of moderate size, to perform the operation of dilatation by the rapid process.

3. If the bladder is irritable, the urine unhealthy, and the stone of large size, to operate by incision after the mode practised by Mr. Fergusson, being careful to avoid incision of the vesical orifice of the urethra, as insisted upon by that gentleman.

I would venture to express the opinion, that careful plugging of the vagina during the first few days subsequent to the operation is a valuable addition to the after treatment, being a means adapted to facilitate rapid healing of the wound, and, as a natural consequence, the due retention of urine in after life.

lymouth, Angust 16th, 1854.

\section{CASE OF DIFTICULT IAAOUR, ITEGBSBI- TATING INSTRUMENTAL ASBISTANCE.}

$\checkmark$

By J. HINTON, Esq.

Dorine the month of March, I was requested to patient, on whom the midrife had already been attending more than fifteen hours.

I gathered the following history. The patient, aged about 30 years, had had four children; the labours had been lingering; but had not required interference. She had now been in labour about twenty-four hours; the membranes had ruptured, with a very copious flow of liquor amnii; since which, the case had progressed very slowly; the pains were feeble, and for some hours they had almost ceased. On examination, I found the brim of the pelvis somewhat contracted, the other portions of the passage were of average size; the presentation was partial face, the brop being the depending portion; the left eye (which was open, and the eyelids very loose and fiabby) and the bridge of the nose could be plainly felt. The point of the nose was somewhat flattened against the pubes, on which it seemed to rest, otherwise the head was not in any way impacted.

As the patient was apparently strong and healthy, and the child most probably dead, I did not hesitate to give the ergot a full and fair trial. The pains which it produced were quite unlike those which generally follow the use of ergot: they were neither very much increased in force, nor was the interval destroyed. The head adranced but slightly; indeed, the pains appeared to be cut short from their full action. She took several doses of ergot, quickly repeated; and as she now appeared to be suffering from the tediousness of the labour, I applied the forceps; but all the force which I dared apply failed to make much impression. Leaving, therefore, the forceps applied, so that, if necessity required, I might use them subsequently to perforating the head, I proceeded to this latter operation.

As the head was by this time dilating the external labia, perforation was easily accomplished; it was followed by a very copious gush of clear liquid, and almost instantly by the birth of the head, before even the blades of the forceps could be removed; the labour was speedily terminated; the placenta, which alhered somewhat firmly, had to be romoved by the hand. The patient progressed very favourably.

After birth, the cause of detention was explained: from the back of the head there extended a large bag, now nearly empty, and reaching to the nates. Apparently, it was an extension of the scalp: and at its junction with the head it was covered with hairs. The neck itself did not measure more than two inches in diameter; and the bag could certainly have contained from two to three pints of fluid. In the occipital bone there was an aperture sufficiently large to admit the point of the finger, and through this the communication with the head was maintained; it was, in fact, similar to spina bifida.

The child had certainly been dead some days. It was a finely made, and in other respects well formed child: the brow and upper part of the face was black and much disfigured.

Blaina Iron Worte, A uguat 14th, 1854. 